\title{
MUSINGS
}

\section{The Human Genome Organisation: towards next-generation ethics}

\author{
Bartha Maria Knoppers ${ }^{1 *}$, Adrian Thorogood ${ }^{1 *}$ and Ruth Chadwick ${ }^{2 *}$
}

Ten years after the completion of the human genome [1], looking back over the policy statements of the Human Genome Organisation's (HUGO) Ethics Committee (EC) and of its Intellectual Property Committee (IPC) is more than just a trip down memory lane; it is the revelation of a seismic shift in the values underlying genomic research (Table 1). Founded in 1992 at the inception of the Human Genome Project, HUGO not only provided prospective scientific leadership on approaches to intellectual property, but also on ethical, legal and social issues. Indeed, the Statements constitute a harbinger of policy debates that persist today.

In the past two decades, genetic research ethics has expanded rapidly from a domain seemingly 'ungoverned by any explicitly ethical or legal norms', to a rich and sophisticated field [2]. Initially, the concerns of the EC and IPC were to ensure participant autonomy through informed consent, respect for participant privacy and confidentiality in light of the sensitive nature of genetic information, and an equitable distribution of the burdens and benefits of genetic research. These concerns are prevalent throughout the HUGO Statements, even as the focus of genetic ethics has shifted from the protection of individuals, families and communities, to considering the broader interests of society, and international harmonization.

\section{Protection of individuals, families and communities Protection of the rights and wellbeing of individual parti- cipants has always been a central concern of research ethics. The 1995 EC Statement expressed fear that 'genome research could lead to discrimination against and stigmatization of individuals and groups', and highlighted the importance of privacy and protecting confidentiality of genetic information [3]. The 1998 Statement affirmed the participant's rights to confidentiality and privacy, and}

*Correspondence: Bartha.knoppers@mcgill.ca; adrian.thorogood@mail.mcgill.ca; ChadwickR1@cf.ac.uk

'Centre of Genomics and Policy, McGill University, Montreal, H3A OG1, Canada ${ }^{2}$ Cesagen, Cardiff University, Cardiff, CF10 3BG, UK suggested concrete mechanisms to protect these rights, such as 'procedures for long term storage, access, and use'. It also stipulated that these procedures be addressed during informed consent [3]. The 2000 IPC Statement stressed that consent is needed from a donor where a patent application is filed for an invention based on biological material of human origin [4].

The familial nature of genetic information and the impact of research on community and population interests have also been of continuing interest. Consent, discrimination and even privacy interests can encompass entire families and communities. The 2007 EC Statement, for example, pointed out that the 'unit of care' may include the family, recommended encouraging voluntary sharing within families [5].

\section{The interests of society}

The EC Statements gradually recognized the 'public good' of genetic databases, going so far as to characterize the human genome as 'part of the common heritage of humanity' in 2000 [3]. In a similar vein, the IPC has consistently discouraged broad patents or, a contrario, the blocking of innovative gene discoveries and patenting by the publication of partial sequences. In 2003, they proposed the establishment of 'a clearing house to expedite the rapid and low cost licensing of patented DNA sequences which have potential applications in clinical diagnosis' to encourage the free availability of raw sequence data [3]. On a related note, the EC Statement on benefit-sharing in 2000 caused quite a stir when it recommended - among other forms of benefit-sharing 'that profit-making entities dedicate a percentage (for example, $1 \%$ to $3 \%$ ) of their annual net profit to healthcare infrastructure and/or to humanitarian efforts' [3]. While the other recommended forms of benefit-sharing did not receive similar press attention, the mere mention of a concrete figure brought attention to the issues of benefitsharing and catapulted patenting-legitimacy, global justice and equitable access issues onto the policy scene.

'Ethics does not consist of a static set of theories or principles that can be 'applied' unproblematically in new situations' [6]. Indeed, a shift can be seen in the HUGO statements towards 'next-generation' ethical issues, 


\section{Table 1. List of HUGO Statements}

HUGO Ethics Committee (now called the Committee on Ethics, Law and Society)
1995/6Statement on the Principled Conduct of Genetics Research [3]
1998 Statement on DNA Sampling: Control and Access [3]
1999 Statement on Cloning [3]
2000 Statement on Benefit-Sharing [3]
2001 Statement on Gene Therapy Research [3]
2002 Statement on Human Genomic Databases [3]
2004 Statement on Stem Cells [3]
2007 Statement on Pharmacogenomics (PGX): Solidarity, Equity, and Governance [4]
2013 Imagined Futures: Capturing the Benefits of Genome Sequencing for Society (unpublished)
HUGO Intellectual Property Committee
1995 HUGO Statement on the Patenting of DNA Sequences [7]
1997 Statement on Patenting Issues Related to Early Release of Raw Sequence Data [4]
2000 Statement on Patenting of DNA Sequences in Particular Response to the European Biotechnology Directive [4]
2003 Statement on the Scope of Gene Patents Research Exemption, and Licensing of Patented Gene Sequences for Diagnostics [4]

HUGO, Human Genome Organisation.

accompanying the emergence of population genomic sequencing technologies. This is especially true in light of genomic science's rapid advancements in the past decade. Scientific advance has also been accompanied by increasing recognition of public ethical concerns, with a shift of focus from individual to communal interests. This shift towards 'next-generation' ethics is reflected in HUGO's $\mathrm{EC}$ and IPC. Indeed, the subsequent change of name of HUGO's EC to the 'Committee on Ethics, Law and Society' exemplifies this shift.

Reciprocity was reconceived as an exchange with communities, rather than individuals, in order to promote participation where research promised no immediate personal benefits. The principles of solidarity, citizenry and universality emerged, respectively fostering responsibility towards the health of others together with individual choice, public engagement with research, and acknowledgement of the human genome as a public good.

The 2007 EC Statement acknowledged 'the fundamental relationship between the quality of scientific research and its ethical acceptability' [5]. The importance of assuring quality in genetic research has grown in importance for several reasons. First, the development of publicly funded population genomic research creates both accountability towards citizens as taxpayers and trust towards potential participants. The EC then changed its name to the 'Committee on Ethics, Law and Society' and quality truly became a centerpiece. Its 2013 draft statement 'Imagined Futures' emphasizes not only high-quality sequencing and interpretation of whole genome sequencing data, but also high-quality storage and accessibility to bioresources (unpublished). Poor quality can also be a barrier to translation of genomic knowledge into clinical applications.
'Imagined Futures' also emphasizes quality even during this translation phase. The culmination of this discussion was the 2013 suggestion to establish a Scientific Advisory Panel able to track developments and provide up-to-date, reliable, and scientifically and clinically validated information.

\section{International harmonization}

Harmonization has remained central to HUGO's discussion. The viability of international collaboration in genetics depends in part on improving access to researchers; this can be hindered by the proliferation of heterogeneous access procedures and ethical guidelines. There is also a risk of overlap between research projects that would result in wasted resources. Earlier statements encouraged compatibility through the use of common nomenclature; the free flow, access and exchange of data; and international coordination and evaluation of development. The IPC has encouraged large-scale centers to adopt a policy of immediate release to secure optimal functioning of and cooperation within international networks. In addition, the IPC has called for the adoption of a harmonized research exemption for patented DNA molecules and their sequences.

While the 'Imagined Futures' Statement maintains a commitment to setting international policy direction, it also reflects a growing consciousness of barriers to harmonization. There is no doubt that now more than ever the Committee on Ethics, Law and Society, along with the IPC, must provide further prospective international harmonization of ethics policy to say nothing of fostering open access databases and non-exclusive licensing. To do otherwise would abandon genetic research to the vagaries of the private sector. 


\section{Abbreviations}

EC, Ethics Committee (HUGO); HUGO, Human Genome Organisation; IPC, Intellectual Property Committee (HUGO).

\section{Competing interests}

The authors declare that they have no competing interests.

Published: 29 April 2013

\section{References}

1. International Human Genome Sequencing Consortium: Finishing the euchromatic sequence of the human genome. Nature 2004, 431:931-945.

2. Knoppers BM, Chadwick R: The Human Genome Project: under an international ethical microscope. Science 1994, 265:2035-2036.

3. HUGO Ethics Committee

[http://www.hugo-international.org/comm_hugoethicscommittee.php]
4. HUGO Intellectual Property Committee [http://www.hugo-international. org/comm_\%20intellectualpropertycommittee.php]

5. HUGO Statement on Pharmacogenomics (PGX): Solidarity, Equity and Governance [http://www.eubios.info/EJAIB92007.pdf]

6. Knoppers $B M$, Chadwick R: Human genetic research: emerging trends in ethics. Nat Rev Genet 2005, 6:75-79.

7. HUGO Statement on the Patenting of DNA Sequences [http://www.humgen.org/]

doi:10.1186/gm442

Cite this article as: Knoppers BM, et al.: The Human Genome Organisation: towards next-generation ethics. Genome Medicine 2013, 5:38. 